\title{
DIREITOS SOCIAIS ÀS AVESSAS: UMA VISÃO PATRIMONIAL DA PROTEÇÃO SOCIAL NA MEDIDA PROVISÓRIA N. ${ }^{\circ}$ 871/19 *
}

\author{
Viviane Freitas Perdigão Lima ${ }^{1}$ \\ Renata Caroline Pereira Reis Mendes ${ }^{2}$
}

\section{RESUMO}

$\mathrm{O}$ estudo reflete a mudança de paradigma no Brasil dos direitos sociais enquanto bens patrimoniais. O referencial teórico pauta-se nos direitos sociais como direitos fundamentais devendo ser garantidos positivamente nas cartas constitucionais, a qual impõe limites e vínculos jurídicos a todos os tipos de Poder (FERRAJOLI, 2011). Metodologicamente foca-se nos princípios constitucionais, na análise documental da Medida Provisória n. ${ }^{\circ}$ 871/19 e suas técnicas. Verifica-se sob o manto de eficiência admnistrativa, um patrimonialismo que abeirase da solidariedade social.

Palavras-chave: Direitos sociais; Direitos fundamentais; Eficiência; Direito Previdenciário

\section{SOCIAL RIGHTS TO EVENTS: A PATRIMONIALIST VISION OF SOCIAL PROTECTION IN PROVISIONAL MEASURE N. ${ }^{\circ}$ 871/19}

\begin{abstract}
The study reflects the change in the paradox in Brazil of social rights as patrimonial assets. The theoretical framework is based on social rights as fundamental rights and should be positively guaranteed in constitutional charters, which imposes limits and legal ties to all types of power (FERRAJOLI, 2011). Methodologically, it focuses on the constitutional principles, the documentary analysis of Provisional Measure No. 871/19 and its techniques. It is under the mantle of administrative efficiency, a patrimonialism that draws on social solidarity.
\end{abstract}

Keywords: Social rights. Fundamental rights. Efficiency. Social Security Right.

\section{INTRODUÇÃO}

Em janeiro de 2019, além de se comemorar o dia Nacional do Aposentado, a Previdência Social completou 96 anos. Tratou-se de uma homenagem à publicação da Lei

\footnotetext{
* Viviane Freitas Perdigão Lima. Mestra em Direito pelo programa Direito e Instituições do Sistema de Justiça da Universidade Federal do Maranhão (UFMA). Professora da Universidade Estadual do Maranhão e Universidade Ceuma. Advogada. http://lattes.cnpq.br/7955567083507463. Renata Caroline Pereira Reis Mendes. Mestra em Cultura e Sociedade pela Universidade Federal do Maranhão. Professora do Instituto Florence de Ensino Superior (IFES). Advogada. http://lattes.cnpq.br/4649996800991390.

${ }^{1}$ Mestra em Direito pelo programa Direito e Instituições do Sistema de Justiça da Universidade Federal do Maranhão (UFMA). Professora da Universidade Federal do Maranhão e Universidade Ceuma. Advogada. http://lattes.cnpq.br/7955567083507463

${ }^{2}$ Mestra em Cultura e Sociedade pela Universidade Federal do Maranhão. Professora do Instituto Florence de Ensino Superior (IFES). Advogada
} 
Eloy Chaves, de 24 de janeiro de 1923, segundo a qual houve a instituição da base do sistema previdenciário brasileiro, por meio da criação da Caixa de Aposentadorias e Pensões para os empregados das empresas ferroviárias.

A Previdência Social, assim como a Seguridade Social, visa alcançar um patamar de bem-estar social prometido em normas constitucionais. Assim, além de contribuir para modernizar a economia dos municípios brasileiros, por meio do pagamento de benefícios, este ramo da Seguridade paga mais de 30 milhões de benefícios somente no Regime Geral de Previdência Social (RGPS), totalizando R \$ 38 bilhões. Destes, mais de 20 milhões são para o pagamento de aposentadorias (por idade, tempo de contribuição e invalidez. (BRASIL, 2019b).

Ocorre que ao lado da vontade de seguro social previsto na Constituição de 1988 corre a onda de pautas de enorme preocupação e atualidade no cenário mundial, sobretudo a sustentabilidade do sistema e o fortalecimento dos mecanismos de financiamento.

A constatação de que a expectativa de sobrevida cresce em todos os segmentos etários, inclusive entre os mais idosos, tem como consequência direta o maior encargo de benefícios, o que demanda frequentes debates sobre a necessidade de reforma da Previdência e a adequação dos direitos assegurados constitucionalmente.

Diante disto, por um lado busca-se a crescente implantação de direitos de titularidade coletiva, de outro, o discurso do déficit de R $\$ 13,8$ bilhões do Regime Geral de Previdência Social. (BRASIL, 2019a).

O presente estudo tem por objetivo refletir sobre a Medida Provisória n. ${ }^{\circ}$ 871/19 e seus desbramentos na proteção social. Para tal, tem-se como escopo a àrea previdenciária que não passa incólume ao mesmo tempo ao discurso deficitário e ferramenta de implantação de efetiva democratização social no Brasil.

A relevância científica do estudo paira no fato de que a MP n. ${ }^{\circ}$ 871/19 além de ser um pente fino nos benefícios previdenciários com possíveis irregularidades ou fraudes, também alcança regras densas em concessão de benefícios, logo, exige discursão da academia e demais agentes envolvidos. No que tange ao enlevo social, as consequencias da referida Medida Provisória poderá ser mecanismo de efetividade e eficiência na gestão pública, assim como, instrumento de não garantia de progresso social.

Como hipótese, o estudo foca no Programa Especial para Análise de Benefícios com Indícios de Irregularidade e o Programa de Revisão de Benefícios por Incapacidade. Contudo, 
não deixando incolume outros matérias afetas a MP n. ${ }^{\circ}$ 871/19 que alcançam o bem-estar social.

O trabalho inova ao discurtir se eficiência e gestão da máquina pública são critérios de urgência e relevância que fundamentem uma Medida Provisória. Ainda mais, se bens sociais fundamentais, como a Seguridade Social, são matérias a ser discutidas por meio de ato unilateral do chefe do executivo.

O referencial teórico pauta-se na perspectiva dos direitos sociais como direitos fundamentais devendo ser garantidos positivamente nas cartas constitucionais, a qual impõe limites e vínculos jurídicos a todos os tipos de Poder. (FERRAJOLI, 2011)

Para a linha metodológica apresenta-se a weberiana deixando-se de lado as categorias sociológicas macroestruturais e detendo-se ao recurso do tipo ideal, para o compromisso explícito com a análise empírica do real. Deste modo, a realidade não possui um sentido intrínseco ou único, visto que são os indivíduos que lhe conferem significados. Assim, sítios eletrônicos do INSS, da Câmara Federal, demais entidades que debatem a Seguridade Social e revisão bibliográfica e análise documental fazem parte do arcabouço metodológico.

O texto está dividido em três seções: a primeira traz reflexões sobre a relevância da Constituição Federal de 1988 na proteção de direitos sociais. Na segunda, focará na concepção dos direitos sociais como direitos fundamentais. Em seguida, estuda-se a MP n. ${ }^{\circ}$ $871 / 19$ como medida propulsora dos direitos sociais enquanto bens patrimoniais. Observa-se que embora a possível disponibilidade estatal de bens sociais, a Constituição de 1988, ainda, assim, diligencia e persegue a justiça e bem-estar social.

\section{AS RACIONALIDADES CONSTITUCIONAIS NA PROTEÇÃO SOCIAL: uma} análise dos princípios orientadores da Seguridade Social

De acordo com Krieger Filho (2018) a Seguridade Social simboliza uma proteção social formulada por princípios e ações destinadas ao individuo, com o fito de garantir-lhes meios de subsistência, assistência e saúde, por meio de responsabilidade dos Poderes Públicos e, também da sociedade. Nesta mesma linha, Vianna (2005) afirma que a proposta da Seguridade é fazer um conjunto de ações baseadas em princípios que busquem o primado da justiça social.

Corroborando com tais preceitos Martinez (2003) e Ibrahim (2011) afirmam que a Constituição de 1988, no artigo 194, não trás tecnicamente uma definição do que seja Seguridade Social. Apenas relacionou seus componentes (conjunto integrado de ações de 
iniciativa dos Poderes Públicos e sociedade) e destinação ( a assegurar os direitos à saúde, à previdência e à assitência social), ainda que a norma constitucional continua sendo encarada como definidora da Seguridade Social brasileira.

O certo é que o termo Seguridade Social foi expressão criada pelo onstituinte de 1988 recebendo críticas de ordem terminológica, pois a locução mais salutar no periodo de redemocratização era segurança e não seguridade. Com tal signo, alcançou-se uma gama de ações que vislumbrou criar uma rede de proteção ainda não vista no país, com forte influência espanhola (IBRAHIM, 2010).

Assim, a Seguridade Social pode ser analisada como um modo de proteção social subsequente ao seguro social implantada em raros países (MARTINEZ, 2003) que conjuga os ideiais de justiça e bem- estar social.

Inserida na sociedade pelo trabalho, a justiça é o fim apontado pela ordem social ( artigo 193 da Constituição de Federal de 1988). Executada pela legislação social, o bem-estar social alinha-se ao ideal de cooperação, de solidariedade alijando-se do individualismo clássico dos estado liberal. Também pode ser definido como erradicação da pobreza e desigualdade mediante a auxílio de todos.

Igualmente, a nação brasileira tem por objetivo a justiça social devendo ser verdadeiro diretriz para os governantes, os quais devem desejar o desempenho distributivo da riqueza nacional. Logo, a justiça social simboliza um "equânime distribuição de benefícios sociais" sendo legitimador de polítcas públicas. Baseia-se nos princípios da seletividade e distributividade necessários a interpretação e aplicação da normatização protetiva. (IBRAHIM, 2010, p. 06).

Partindo da ideia de que os princípios são fundamentos de regras que encontram-se na base ou contribuem para razão das regras jurídicas (CANOTILHO, 1993) que formulam mandamentos ou mandados de otimização (ALEXY, 2008), os princípios Constitucionais, que regem a Seguridade Social, são aqueles elencados imediatamente no artigo 194, nos termos dos incisos do parágrafo único, da Constituição Federal. Ademais, também são reforçados no parágrafo único do art. $1^{\circ}$ da Lei 8.212/91. (BRASIL, 1991).

Contudo, é ideal compreender que a concepção de rede protetiva composta pelo Estado e por particulares, com contribuição de todos incluindo parte dos beneficiários dos direitos, "[...] no sentido de estabelecer ações para o sustento de pessoas carentes, trabalhadores em geral e seus dependentes, providenciando a manutenção de um padrão mínimo de vida digna” depende dos chamados princípios gerais da Seguridade Social. 
Assim, a proposta dos princípios gerais é aclarar o alcance, a importancia e valores do bem-estar e justiça sociais, que são segundo Balera (2005), bases do Estado brasilerio, bem como diretrizes de sua atuação. Para o autor, a Seguridade é um importante meio para se alcançar a justiça, fim último da ordem social.

Um primeiro princípio a ser elencado é o da igualdade. Significa que a rede protetiva de Seguridade Social deve ser pensada diante de suas ações dentro de uma perspectiva de que os iguais são tratados de modo igual e os desiguais de modo desigual, dentro do limite de suas desigualdades, como já havia elencado Rui Barbosa e tratada no artigo $5^{\circ}$, I da Constituição Federal de 1988. Trata-se de uma isonomia material ou geográfica. A ideia é saber em até que ponto a desigualdade não gera inconstitucionalidade.

Outro princípio norteador é o da legalidade. O princípio da legalidade surgiu diante do Estado de Direito e apresenta como faceta de oposição a toda e qualquer forma de poder seja ele autoritário ou contra a democracia. Tal é visualizado no art. $4 .^{\circ}$ da Declaração dos Direitos do Homem e do Cidadão de 1879. Já na conjuntura normativa brasileira, os artigos 5. ${ }^{\circ}$, II; 37; e 84 , IV, da CF/88 demonstram que o referido princípio deve ser observado de forma diferente para o particular e para a administração.

No que se refere a Administração Pública, está só pode fazer o que a lei permite. Para as relações entre particulares, o princípio aplicável é o da autonomia da vontade, ou seja, é permisssível fazer tudo o que a lei não proíbe. (DI PIETRO, 2018).

A par disto, “[...] a Administração Pública não pode, por simples ato administrativo, conceder direitos de qualquer espécie, criar obrigações ou impor vedações aos administrados; para tanto, ela depende de lei”. (DI PIETRO, 2018, p. 136).

O princípio da legalidade, mesmo sendo salutar para os demais ramos do direito, sobretudo para o ramo Previdenciário, indica que qualquer nova obrigação (principal ou acessória), por exemplo defesa em suspensão de benefício por incapacidade, somente será feito por lei em sentido formal. Assim, deve ser discutido pelo Congresso Nacional ou de forma excepcional por meio de Medida Provisória.

Segundo Lenza (2018, p. 1145) a Medida Provisória é adotada pelo chefe do executivo federal, “[...] por ato monocrático, unipessoal, sem a participação do Legislativo, chamado a discuti-la somente em momento posterior, quando já adotada pelo Executivo, com força de lei e produzindo os seus efeitos jurídicos."

A ideia de Medida Provisória, em caso de relevância e urgência, nos moldes do artigo 62 da CF/88 afirma que o Presidente da República poderá adotar medidas provisórias 
com força de lei, devendo submetê-las de imediato ao Congresso Nacional. Ocorre que ta ideia foi posteriormente modificada pela EC n. ${ }^{\circ} 32 / 01$. O objetivo foi eliminar distorções e manter a segurança jurídica que não eram observadas durante o regime militar, visto que havia uma abuso na função legislativa atípica por intermédio do decreto-lei.

Ainda pertencendo aos limites da retroatividade da lei (art. 5. ${ }^{\circ}$, XXXVI) e com a proposta de garantir a estabilidade às relações jurídicas, a Constituição Federal dispõe que a lei não prejudicará o direito adquirido, o ato jurídico perfeito e a coisa julgada. Assim, como princípios informadores da Seguridade Social compete a inclusão do direito adquirido, ato jurídico perfeito e da coisa julgada.

Enquanto coisa julgada significa que a decisão judicial de que não caiba mais recurso e ato jurídico perfeito o ato já consumado segundo a lei vigente ao tempo em que se efetuou, o direito adquirido remonta segurança jurídica. Nos moldes do artigo $6^{\circ}$, §2, da Lei de Introdução das Normas do Direito Brasileiro é o direito que o seu titular, ou alguém por ele, possa exercer, como aquele cujo começo do exercício tenha termo pré-fixo, ou condição preestabelecida inalterável, a arbítrio de outrem. (BRASIL, 2010)

Significa que é aquele direito que pertence ao patrimônio jurídico e não patrimônio econômico da pessoa, desde o momento que alcançou todas as condições para esse fim podendo manejá-la a qualquer momento. É o caso da pessoa, por exemplo, já ter implementado os requisitos de uma aposentadoria, mas norma posterior modificou as técnicas de concessão, mesmo assim a aposentadoria já pertencerá ao seu patrimônio jurídico. (MARTINS, 2000)

Cabe ressaltar que o direito adquirido, não pode ser alegado em face da manifestação do poder constituinte originário, uma vez que este é incondicionado e ilimitado juridicamente. Em que pese se tratar de manifestação do Poder Constituinte derivado reformador, em virtude do limite material da cláusula pétrea prevista no art. $60, \S 44^{\circ}, \mathrm{IV}$, entende-se que os direitos adquiridos deverão ser preservados.

Previsto como objetivo fundamental da República Federativa do Brasil (artigo $3^{\circ}$ ), o princípio da solidariedade é tratado como um princípio estruturante que orienta políticas governamentais sendo consagrado como direitos de $3^{\circ}$ dimensão. Revela-se na concepção de igualdade entre os povos, na dignidade da pessoa humana e na justiça social.

O princípio da solidariedade ou fraternidade visualiza o ser humano inserido em uma coletividade em que se propõe direitos além dos interesses do indivíduo. Concerne ao abrigo 
do gênero humano postulando-se universidade, humanismo, irmandade e senso de comunidade.

A ideia de solidariedade significa a promoção e alcance de direitos a todos que consequentemente acaba por promover a autonomia individual e cidadania plena. Para Martins (2000) é essencial e um postulado fundamental para a Previdência Social, pois sem ele seria considerado irrealizável à organização da Seguridade Social.

Martinez (2003) traduz a solidariedade como cooperação da maioria em face da minoria, ou seja, do todo em direção ao individual. Busca transformar as parcelas, de cada pessoa envolvida, em um conjunto, com a finalidade de conceder os benefícios e proteger o sistema da seguridade social.

De tal modo, a solidariedade social acaba sendo um verdadeiro princípio fundamental do Direito Previdenciário. Em verdade, mostra-se como uma espécie de cotização coletiva em face daqueles que necessitem ou necessitarão de prestações sociais.

Diante de tais reflexões os princípios explicitados devem nortear o legislador ao fazer políticas sociais em matéria de Seguridade Social. A Constituição deve ser interpretada em sua globalidade dentro de preceitos integrados e único de regras e princípios. A ideia é harmonizar os espaços de tensões entre a legislador ordinário e as garantias constitucionais.

Cabe ao legislador, como representante da sociedade, ao discutir matérias em políticas públicas basear-se na vontade constitucional. Trata-se de manter uma concepção integracionista entre Estado e Sociedade onde as conflitualidades sejam resolvidas dentro de uma perspectiva racionalizada da Constituição capaz de produzir soluções plurais que integrem as pessoas.

\section{DIREITOS SOCIAIS COMO BEM FUNDAMENTAL: por um garantismo jurídico em face do custos dos direitos}

Segundo os ensino de Ferrajoli (2011) os direitos fundamentais são todos aqueles tratados como subjetivos que falam sobre todos universalmente como seres humanos eivados do status de pessoa ou de cidadão ou de pessoa capaz de agir. Para tal concepção, o autor parte do pressuposto de que o direito subjetivo é qualquer expectativa positiva, ou seja, a uma prestação, ou negativa, a não sofrer lesão que esteja vinculado a um sujeito por meio de uma norma jurídica. 
No que se refere a status, demonstra a condição de um sujeito notável em uma norma jurídica positiva como requisito de sua idoneidade a ser o titular de demandas jurídicas. (FERRAJOLI, 2011).

Para o autor, a ideia de direitos fundamentais embora possivelmente determinada pelas leis e cartas constitucionais modernas não depende da circunstância de fato de que nesse ou naquele ordenamento tais direitos estejam ou não formulados em dispositivos constitucionais ou legislação infraconstitucional. Logo, os direitos fundamentais existem e devem ser observados mesmos que eles sejam ou não enunciados em dispositivos normativos. (FERRAJOLI, 2011).

Ademais, cabe salientar que os direitos fundamentais dentro de uma perspectiva estrutural ou formal independe da natureza dos interesses e das necessidades tuteladas para ser reconhecido como fundamental. Isto porque se baseia em um carater universal de sua imputação, ou seja, são universais em seu sentido lógico e avalorativo para quais classes são destinados. Assim, para Ferrajoli (2011) são fundamentais, logo, universais, os direitos de liberdade pessoal e de pensamento, os direitos políticos, direitos sociais e outros direitos que sejam similares a estes.

Na perspectiva de Ferrajoli ( 2011) qualquer que seja o ordenamento jurídico são feitos escolha sobre direitos fundamentais em relação aos direitos humanos ( direitos primários) tal qual a vida e integridade, liberdade, à saúde e instrução), direitos públicos (direitos primários reconhecidos socialmente pelos cidadãos como direito de residência, reunião, circulação, trabalho, subsistência e assitência), direitos civil (capacidade de agir como negociação e contratação) e direitos políticos ( para os cidadãos capazes de agir como o direito ao voto e acesso as funções pública, por exemplo). Contudo, desde que sejam ofertados universalmente as classes de sujeitos identificados como pessoa, cidadão ou com capacidade de agir.

Ferrajoli (2011) para definir os direitos fundamentais, trás a tona quatro teses que corroboram com a ideia de que os mesmos são protegidos por um garantismo jurídico. Serve para balizar e vincular o poder quer público ou privado.

Em sua primeira tese, os direitos fundamentas não se confundem com os direitos patrimoniais, pois os fundamentais refere-se à inteira classe de sujeitos, enquantos os patrimoniais refere-se a qualquer de seus titulares, excluindo-se todos os outros. A proposta pauta-se no Segundo Tratado sobre o Governo de John Locke, de 1690 que diferencia três direitos (vida, liberdade e propriedade) cuja garantia justificam o contrato social. 
A interpretação dos direitos fundamentais como interesse e expectativas de todos compondo o fundamento e o parâmetro da igualdade jurídica, Ferrajoli (2011) propõe sua segunda tese. Porta-se como o conjunto das garantias asseguradas pelo paradigma do Estado de Direito, mesmo modelado pelas origens do Estado moderno tutelando de início somente direitos de liberdade e propriedade tornou-se depois vinculado a outros direitos de expectativas vitais como saúde, assistência e previdência.

Ao avizinhar os direitos fundamentais a sua natureza supranacional criou-se a terceira tese. Significa que após a composição em convenções internacionais recepcionadas pelas cartas nacionais os direitos fundamentais volvem-se de seu caráter supraestatal “(...) limites externos, e não somente internos, aos poderes públicos e base normativa de uma democracia internacional bem distante de ser atuante, mas por esses direitos normativamente pré-figurada. (FERRAJOLI, 2011, p. 16).

Em última tese, Ferrajoli (2011) discute a definição de direitos fundamentais dentro das relações entre os direitos e garantias. Para o autor, os direitos fundamentais significam expectativas positivas ou negativas, que correspondem a prestações (deveres) ou lesões (proibições). Tais são vistos como garantias primárias e como secundárias aqueles deveres de reparação judicial a lesões das garantias primárias. Ressalta que para os deveres quanto para as proibições são constantemente não apenas violados, mas se quer estão previstos nas normas internas.

Diante de tais teses observa-se que a definição de diretos fundamentais falam sobre os direitos universalmente dirigidos a todos enquanto pessoas e/ou cidadãos e/ou pessoas com capacidade de fato, descritas imeditamente por normas. Como consequencia, são indisponíveis e inalienáveis. Universais, em que pese ser seu defrute acessível a todos enquanto pro indiviso, ou seja, podendo ser manejado por todos e cada um de maneira exclusiva, não sendo deixados à disposição, assim como, à propriedade privada e a livres disposições das instâncias de poder.

Diante da definição de direitos fundamentais cabe abarcá-los como bens, mas fundamentais e não patrimoniais. Tal ideia é importante para o momento em que os direitos sociais (previdênciário, por exemplo), como direito fundamental que é se avizinha do discurso da necessidade de efetividade por meio de escolhas orçamentárias/ deficitárias.

Na visão de Ferrajoli (2007) bens são tudo aquilo que pode ser objeto de uma situação jurídica, ou seja vai além daquilo que não se encaixa como coisas nem bens patrimoniais, mas que são relevantes enquanto objeto de tutela e de disciplina jurídica. 
Assim, bens em sua perspectiva patrimonial não se confunde com bens fundamentais. Bens patrimoniais são aqueles disponíveis no mercado por meio de atos de disposição ou até mesmo de troca. São direitos que indicam de maneira singular os seus titulares excluindo-se os demais. São não apenas dispostos, mas, sobretudo, predipostos por normas ( por exemplo, o Código Civil/2002, artigo 1.225). São, em regra, disponíveis e alienáveis. São bens que tenham por objeto um direito patrimonial.

Diferentemente dos patrimoniais, os bens fundamentais dotam acessibilidade para todos e a cada um, pois objeto de outros tantos direitos fundamentais e, deste modo, não se submetem à logica de mercado (como os direitos sociais, tais a saúde universal, a assistência aos necessitados e a previdência aos segurados). Logo, são bens fudamentais qualquer bem que se tenha por objeto um direito fundamental primário (o ar, a água, o patrimônio ecológico, os fármacos distribuídos pelo SUS, os benefícios previdenciários rubricados por incapacidade).

Os bens fundamentais apresentam garantia de indisponibilidade. Significa que que eventual disposição dos mesmos é inexistente. Para os bens patrimoniais, uma possível disposição alheia aos moldes do direito positivo constituiria apenas ato ilícito. "[...] Pelo contrário, a venda ou destruição de um bem fundamental são fatos, talvez irreversíveis, dos quais o direito não pode impedir a sua correta comissão, mas somente proibí-la ou puní-la como ilícita" (FERRAJOLI, 2011, p. 56).

Ademais, cabe ressaltar que na visão da ciência jurídica a natureza patrimonial ou fundamental de um bem depende do direito positivo. Assim, um direito positivo transforma um bem social (fundamental) em patrimonial se os direitos ditos sociais tornarem-se disponíveis; de modo diverso, se um bem patrimonial (por exemplo, uma casa) torna-se fundamental se fosse obrigatória a sua distribuição para todos.

Sendo assim, os bens patrimoniais, enquanto direitos patrimoniais, podem ser utilizados (ius utendi) e dissipados (ius abutendi). “[...] os bens fundamentais são objeto de direitos fundamentaisenquanto e somente enquanto são objetos de limites e vínculos, ou seja, das proibições de disposições ou de obrigações correspondentes aos mesmos." (FERRAJOLI, 2010, p. 56).

Neste perfil, Ferrajoli (2011) relaciona os bens fundamentais aos bens sociais. Como bens sociais, o autor denomina os direitos que apresentam como objeto prestações, tais como a alimentação básica e assitência sanitária. São aqueles produzidos e distribuidos pelo homem e que são convencionados como tais, pois são vitais e devem ser juridicamente acessíveis a 
todos. São fundamentais em seu sentido subjetivo, visto que é destinado para quem não está em condições de adquirí-los como bens patrimoniais. Pertencem aos bens fundamentais na medida em que são objeto dos direitos sociais determinados nas cartas constitucionais.

A garantia a aquisição universal de bens sociais é praticável apenas com a eliminação da lógica de mercado aliado à atribuição a esfera pública de sua distribuição e, até mesmo sua produção (FERRAJOLI, 2011). Os bens sociais poderam tonar-se patrimoniais apenas naquilo que excede o mínimo existêncial. Ocorre que alguns direitos sociais, como os benefícios por incapacidade, são para muitos idosos necessários a sua sobrevivência.

Mesmo que os direitos sociais custem (HOLMES; SUNSTEIN, 2000), o custo de sua ausência é muito maior. O constitucionalismo dos bens sociais é de extenso tempo: com a experiência dos países ricos ensina, o investimento em despesas sociais significa o “[...] primeiro investimento produtivo, dado que realiza, com a garantia dos mínimos vitais, a primeira condição da produtividade tanto vital quanto coletiva e portanto do desenvolvimento econômico.” (FARRAJOLI, 2011, p. 76).

Mesmo sabendo-se da realidade europeia de Ferrajoli (2011), as definições traçadas são pertimentes para a realidade dos direitos sociais no Brasil. Assim, urge tratá-los como direitos fundamentais, bens fundamentais em face da tentativa de torná-los patrimoniais com a Medida Provisóaria n. ${ }^{\circ}$ 871/19. A juridicidade de uma norma deve depender de sua intrínseca relação de justiça e racionalidade e não somente de sua positividade, isto é, o simples fato de ser imposta pelo gestor público na forma prevista pelo rito cosntitucional.

É preemente que se mantenha o constitucionalismos que resultou da positivação dos direitos fundamentais como limites as ondas mercadológicas do legislador. É fundamental que se observe as racionalidades constitucionais diante da onipotência do legislador. Assim, para maior discussão do tema se buscará em tópico seguinte a análise da referida Medida Provisória n. ${ }^{\circ}$ 871/19 e os desassossegos ao direito fundamental à Previdência estável, ou seja, sem os assombros econômicos.

\section{MEDIDA PROVISÓRIA N. ${ }^{\circ}$ 871/19: uma concepção de direitos sociais como bens patrimonias}

Com a notícia de que deve-se preservar o equilíbrio financeiro e atuarial (artigo 201, CF/88) do sistema, de defict desde 1995 no RGPS, com o crescimento das despesas com o pagamento de benefícios e redução de receitas, além de aprovação do limite de gastos, imposta pela Emenda Constitucional $n^{\circ}$ 95, de 15 de dezembro de 2016, melhoria da gestão 
dos benefícios, maior eficiência na atuação do INSS, melhorando os instrumentos de combate a fraudes e rápida apuração de benefícios com suspeita de irregularidade, ajustes na legislação visando reduzir divergências de interpretação que resulta em ações judiciais, o Executivo Federal publicou a MP n. ${ }^{\circ} 871 / 19$.

Vê-se que a referida MP possui como elementos de relevância direitos fundamentais sociais e como requisito de urgência pauta econômica deficitária do Regime Geral da Previdência Social. Aliado a tais acresce-se a necessidade de urgente performance eficiente e utilitária do orgão gestor da Previdência Social, o INSS.

De acordo com a pauta da fatídica MP, compete ao Instituto Nacional do Seguro Social (INSS) a instituição de dois programas: o Programa Especial para Análise de Benefícios com Indícios de Irregularidade e o Programa de Revisão de Benefícios por Incapacidade. Ambos desencadearão uma bonificação para os servidores públicos que participarem de tais planos, respectivamente o Bônus de Desempenho Institucional por Análise de Benefícios com Indícios de Irregularidade do Monitoramento Operacional de Benefícios (BMOB), no valor de $\mathrm{R} \$ 57,50$ por processo integrante do Programa Especial concluído, e o Bônus de Desempenho Institucional por Perícia Médica em Benefícios por Incapacidade (BPMBI), no valor de $\mathrm{R} \$ 61,72$, por perícia extraordinária realizada.

Segundo a proposta do Executivo Federal, as bonificações tem a finalidade de reforçar a necessidade de "motivação dos atos dos servidores" do INSS ao atuarem na análise administrativa quer seja de revisão ou bonificação de benefícios previdenciários.

Ocorre que a referida bonificação, assim como a realização de todo o programa gerará um gasto de $\mathrm{R} \$ 339,3$ milhões. Para 2019, R \$ 223,8 milhões ( $\mathrm{R} \$ 100,4$ milhões para o BMOB e R \$ 123,4 milhões para o BPMBI), e R\$ 115,5 milhões no exercício de 2020 (R\$ 25,1 milhões para o BMOB e R\$ 90,4 milhões para o BPMBI), visto que os programas poderão ser prorrogados até 2022.

Em contrapartida, segundo a exposição de motivos da MP, tal apresentará como estimativa de economia, em doze meses, de aproximadamente $\mathrm{R} \$ 9,8$ bilhões, já descontados os gastos com os programas. Sendo assim, percebe-se que um intenso jogo de valores são colocados para se confirmar a necessidade de reformas na Seguridade Social.

Termos como "eficiência", "eficácia", "gestão de benefícios", "controle dos gastos públicos", "combate a fraudes", "efeitos fiscais", "rapida apuração" são acentuada como primordial importancia em uma rede protetiva social. Ocorre que para agenda da Seguridade Social, tais conceitos devem desencadear imediatamente justiça e bem-estar social. Logo, 
deve ser analisado como a aproximação de conceitos econômicos à proteção social redundará em redução das desigualdades sociais, visto que é uma tarefa que exige esforço dos Poderes com o fito de alcançar uma sociedade mais justa.

Enfim, a exposição de motivos não esclarece como tais combates e eficiências promoverão a médio e longo prazo (2019 é o início do programa até sua possível prorrogação em 2022) a redistribuição de renda e a assistência aos menos favorecidos. Não fala como ocorrerá a promoção do hipossuficiente ao poder cessar um benefício previdênciário com "irregularidade" caso o segurado não se defenda em dez e não recorrer em trinta dias (artigo $69, \S \S 1^{\circ}$ e $5^{\circ}$, MP n. $\left.^{\circ} 871 / 19\right)$.

De acordo com a MP, o INSS poderá cessar, suspender cauterlamente e até bloquear benefícios previdenciários com indícios de irregularidade na concessão e revisão dos mesmos.

O problema está na forma como a norma unilateral do chefe do executivo desencadeia tais eventos (artigo 69). No que tange a notificação esta poderá ser por meio postal (por carta simples) de acordo com o endereço disponibilizado pelo beneficiário, por meio de rede bancária ou notificação eletrônica, dando-se preferência a via bancária.

Ocorre que tais formas de notificação podem resultar facilmente em ausência de defesa do beneficiário, pois fica a cargo de agentes alheios a responsabilidade imediata da proteção de direitos sociais. Para o INSS pode ser mais eficiente e eficaz disponibilizar para terceiros a comunicação do evento irregular, mas deveria atentar-se em como coibição possíveis irregularidades desses agentes na realização das notificações.

Ademais, a própria MP indica como fator de suspensão de benefício a chamada defesa insuficiente e defesa desconsiderada. O que a Adminsitração Pública entende por defesa insuficiente e desconsiderada? São situações que poderão aumentar a judicialização, visto que cabe a Administração Pública segundo o princípio da legalidade fazer o que determina a lei. Contudo, em nada a MP esclarece o que se enquadra como defesa insuficiente e desconsiderada, visto que a mesma pode ser feita inclusive oralmente pelos canais de atendimento do INSS (art. 69, $\S 3^{\circ}$ ).

A MP n. ${ }^{\circ}$ 871/19 altera a legislação previdência não apenas para coibir irregularidades e fraudes de benefícios elencadas pelo Tribunal de Contas da União, Controladoria Geral da União e Força- Tarefa Previdenciária cujos titulares estão usufruindo dos mesmos. Mas adentra na possibilidade de quebras de sigilo em irregularidades no BPC e na suspeita de óbito do beneficiário. 
Assim, após a identificação do depósito indevido na conta bancária do segurado ou do pensionista já falecido, o órgão pagador inicia o processo de solicitação da restituição do valor creditado às instituições financeiras. Tais valores serão restituindo quarenta e cinco dias após o requerimento de restituição. O relevante para esta situação é que a MP tem efeito ex tunc, ou seja, trás a possibilidade de se aplicar tal regra antes da sua entrada em vigor.

Com discurso imediato de coibição de fraudes e irregularidades e eficiência na gestão da coisa pública, a MP acaba, indiretamente por alcançar substancialmente a concessão de benefícios previdenciários, ou melhor, no próprio direito a um seguro social:

a) Comprovação do direito passará a ser exigido início de prova documental contemporânea de união estável e dependência econômica. Sendo vedado a inscrição pós óbito de contribuintes individuais e facultativos.

b) Estabelecimento de prazo de até cento e oitenta dias para se ter direito a receber o benefício de forma retroativa à data do óbito no caso dos filhos menores de 16 anos.

c) Carência para auxílio doença de doze meses e vinte e quatro meses para auxílio-reclusão. Ainda, decai em cento e oitenta dias a partir do parto ou adoção o direito ao salário maternidade

d) Comprovação da condição e do exercício da atividade rural do segurado especial ocorrerá exclusivamente pelas informações constantes Cadastro Nacional de Informações Sociais - CNIS,em cooperação Ministério da Agricultura, Pecuária e Abastecimento e com outros órgãos da administração pública federal, estadual, distrital e municipal, deste que cadastrado até até 30 de junho do ano subsequente.

Ademais, a MP n. ${ }^{\circ} 871 / 19$ altera a Lei $n^{\circ} 8.112 / 90$ no que tange ao regramento da pensão por morte e, também alcança a Lei $\mathrm{n}^{\circ}$ 8.009/90 para proibir a impenhorabilidade do bem de família em decorrência de benefício previdenciário ou assistencial recebido indevidamente por dolo, fraude ou coação.

Das situações demonstradas, percebe-se que o discurso de maior eficiência e eficácia da ação estatal voltada para a gestão de benefícios, viabilizando o devido controle dos gastos públicos torna os direitos sociais em bens patrimonias. Isto porque os mesmos adotaram a perspectiva de disponibilidade. (FERRAJOLI, 2011).

Apesar de adotar posturas de enrijecer as regras de aposentadoria e pensão foi previsto uma renúncia de $\mathrm{R} \$ 54,56$ bilhões com isenções previdenciárias dentro do próprio ano de craição da MP n. ${ }^{\circ}$ 871/19. Por exemplo, em 2018, para as renúncias a micro e pequenas empresas ( $\mathrm{R}$ \$ 25,8 bilhões), microempreendedor individual ( $\mathrm{R}$ 2,2 bilhões) 
entidades filantrópicas e exportadores agrícolas totalizaram R\$ 46,3 bilhões. (ESTADÃO, 2019).

A MP n. ${ }^{\circ} 871 / 19$ adota a agenda social como bem patrimonial e não como bem social. Trata benefícios como coisas que além de possuir valor de uso apresenta um valor de troca no sentido de que é possível tanto dispor quanto trocar no mercado. (FERRAJOLI, 2011).

Cabe analisar de forma uniforme e integral a vontade do Constituinte de 1988. A Constituição como norma superior deve impor limites rigorosos ao mercado e, por outro lado, como garantia dos bens sociais, vincular a política para torná-los acessíveis a quem necessitar.

Se é verdade que todo direito tem um custo, ou seja, necessitam de dinheiro público para serem protegidos ou cumpridos, o custo pela sua ausência pode ser muito maior. O aumento crescente de desemprego, saúde e educação de qualidade podem ser consequencias das permanentes reformas nos direitos sociais.

Parece-se que os obstáculos ao cumprimento da Constituição de 1988 são de relance político, visto que a norma constitucional orienta-se pela busca incessante na impossibilidade de redução das implementações de direitos fundamentais que já tenham sido realizados. É necessário a realização política das garantias constitucionais.

É certo que o bem-estar promovido pelos direitos sociais é dispendioso, pois exige a retirada e redistribuição de recursos. É um tanto incompatível com a lógica de mercado, ou melhor, é limitado pelo mercado. Não deveria ser visto, os direitos sociais, como escolha. Não foi este o tratamento lançado, garantido e oponivel pela Constituição contra qualquer instituição e Poder.

Correto é que levar a sério os direitos sociais proclamados a nível interno requer que se tenha em discursão a aplicação dele para cada um de nós universalmente, não podendo ninguém ser privado. São indisponíveis ativa e passivamente, visto que não são expropriáveis ou limitáveis por qualquer sujeito comecando-se pelo Estado.

\section{CONSIDERAÇÕES FINAIS}

A ideia de proteção social, ou seja de bem-estar passou por momentos que vão desde as primeiras experiências até o contexto atual de encolhimento protecional. Assim, o seguro social caminhou do embrião da Previdência com Otto von Bismarck, passando pela sua implantação a nível Constitucional, com as Constituições Mexicana de 1917 e de Weimar de 1919, após, pela expansão com as ideias do economista Keynes com a concepção de 
universalização e solidariedade do sistema até o último momento de retrações da promoção social.

No que se refere aos motivos de tal encolhimento pode ser apontado redução nos postos de trabalho em vista da automoção controle e tecnologia da informação, a chamada industria 4.0, inversão de pirâmide etária, redução da taxa de fecundidade, elevado crescimento dos gastos públicos e fim da sequencia de prosperidade econômica. Vê-se que tais indicativos estão diretamente relacionados com a fase de expansão da proteção social, ou seja, universalidade e solidariedade do sistema.

Em que pese tais acontecimentos, o Brasil não pasa incólume. Apesar de ter ocorrido a constitucionalização dos direitos sociais e políticos, ou seja um espécie de garantia formal de tais direitos, a presente proposta de redução de gastos públicos com políticas sociais, demonstra que não atingiu o prometido Bem-Estar Social, conforme ocorreu com alguns Estados no momento expansionista de seguro social.

Neste contexto, a Medida Provisória n. ${ }^{\circ} 871 / 19$ com o discurso de maior eficiência e eficácia para gestão de benefícios, viabilizando o devido controle dos gastos públicos e evitando o aumento indevido de despesas e do deficit público simboliza tonar os direitos sociais enquanto bens disponíveis, ou seja, patrimoniais.

Embora o princípio da eficiência encarnado pela EC n. 19/98 encabece a ideia de uma administração que deva realizar suas atribuições com diligência, plenitude e rendimento funcional, a Constituição Federal afirma que não deve se confundir com a eficiência das associações privadas. Ademais, não pode ser visto como uma aptidão absoluta diante dos demais princípios. Por exemplo, o da dignidade da pessoa humana.

Assim, as demandas da MP em comento devem ser observadas com cautelas. Como um exemplo, deve-se atentar para seus requisitos instrumentais de cessação e suspensão de benfícios, visto que precisa ser observado as desigualdades regionais. A depender do local do país, muitos idosos, em face do seu nível educacional, poderão não saber responder satisfatoriamente a notificação do órgão gestor da previdência.

Desde modo, antes do Estado brasileiro adentrar em reformas estruturais, ou seja, modificar severamente o sistema público incluindo elemento privado (lógica de mercado com bonificações) como complemento ao público deveria adotar medidas que coadunem com a vontade Constitucional.

Assim, a Administração será eficiente, nos moldes do artigo 37 da CF/88 ao atender satisfatoriamente as necessidades da comunidade e observar ao dever de boa administração 
para não reproduzir a ideia de que a Previdência é deficitária. Antes, deve tomar e promover posturas administrativas que se alinhem com a Carta Constitucional de 1988.

Logo, necessário se faz a observância pela Administração Pública da chamada Compensação Previdenciária, o chamado Comprev, entre o INSS e os Regimes Próprios de Previdência Social (RPPS), além das renúncias previdenciárias (por exemplo, Simples Nacional, entidades filantrópicas, microempreendedor individual e exportação da produção rural).

Ainda, acresce-se a necessidade de criação de Lei de Responsabilidade Previdenciária e o que já foi pontado pelo relatório da CPI da Previdência Social o reexame do modelo adotado para elaboração das avaliações atuariais do RGPS e do RPPS sobre às projeções de crescimento do PIB, produtividade, indicadores demográficos, taxas de mortalidade, receitas e despesas com benefícios presentes e futuros, e demais fatores relevantes. Isto porque visa-se evitar os erros de estimativa quanto ao déficit.

Cabe a reavaliação das premissas utilizadas na inclusão das despesas com RPPS, para os servidores civis e militares, sob a patuta da seguridade social. Além disso, o refinamento de programações estranhas ao conteúdo constitucional de Seguridade Social anexadas pela Administração como seu orçamento.

Enfim, os R\$ 175 bilhões correspondentes de débitos recuperáveis de empresas privadas devedoras da Previdência, conforme aponta a Procuradoria da Fazenda Nacional supera os projetáveis $\mathrm{R} \$ 9,8$ bilhões que a MP n. ${ }^{\circ}$ 871/19 apresentará como estimativa de economia, em doze meses. A diferença é que a referida MP poderá ser um mecanismo de redefinição do papel estatal na consecução de direitos fundamentais.

Ante o exposto, há uma inversão dos direitos sociais. Tais estão sendo encarados como patrimoniais, disponíveis, alienáveis. Exigem uma atuação positiva, promocional do Estado, visto que são direitos cujos titulares é a prória coletividade. Ocorre que são instamente direitos fundamentais, logo, dotados de carater universal e indisponíveis podendo ser empunhado por todos e cada um de maneira exclusiva, não sendo deixados à disposição de qualquer Poder.

Liga-se a fraternidade e solidariedade que são a vontade, essência constitucional. Os direitos sociais fundam-se no desenvolvimento, ao progresso e autodetreminação dos povos. São direitos fundamentais, pois independe da natureza dos interesses e das necessidades tuteladas. Igualmente, compete ao Estado assegurar o bem comum da coletividade que o compete, não pode tratá-los as avessas. 


\section{REFERÊNCIAS}

ALEXY, Robert. Teoria dos direitos fundamentais. Trad. Luís Virgílio Afonso da Silva. São Paulo: Malheiros, 2008.

BRASIL. LEI N. ${ }^{\circ} 12.376$ de 30 de dezembro de 2010. Lei de Introdução as Normas do Direito Brasileiro. Diário Oficial da União de 31/12/2010, P. 2. Disponível em: http://legislacao.planalto.gov.br/legisla/legislacao.nsf/Viw_Identificacao/lei\%2012.3762010?OpenDocument. Acesso em: 10 mar 2019.

. Medida Provisória n. ${ }^{\circ} 871$ de 18 de janeiro de 2019. Institui o Programa Especial para Análise de Benefícios com Indícios de Irregularidade, o Programa de Revisão de Benefícios por Incapacidade, o Bônus de Desempenho Institucional por Análise de Benefícios com Indícios de Irregularidade do Monitoramento Operacional de Benefícios e o Bônus de Desempenho Institucional por Perícia Médica em Benefícios por Incapacidade, e dá outras providências. Diário Oficial da União de 18.1.2019. Edição extra - N. ${ }^{\circ}$ 13-A. Disponível em: http://www.planalto.gov.br/ccivil_03/_Ato2019-2022/2019/Mpv/mpv871.htm. Acesso em: 10 mar 2019.

MINISTÉRIO DA ECONOMIA. Secretaria de Previdência. Previdência Social registra deficit de 13,8 bilhões em janeiro. Disponível em:

http://www.previdencia.gov.br/2019/03/previdencia-social-registra-deficit-de-r-138-bilhoesem-janeiro/. Acesso em: 31 mar 2019.

Previdência completa 96 anos pagando mais de 30 milhões de benefícios.

Disponível em: http://www.previdencia.gov.br/2019/01/previdencia-completa-96-anospagando-mais-de-30-milhoes-de-beneficios/. Acesso em: 31 mar 2019.

SENADO FEDERAL. CPI da Previdência aprova relatório final por unanimidade.

Disponível em: https://www12.senado.leg.br/noticias/materias/2017/10/25/cpi-daprevidencia-aprova-relatorio-final-por-unanimidade. Acesso em: 31 mar 2019.

BALERA, Wagner. Sistema de Seguridade Social. São Paulo: RT, 2000.

BONAVIDES, Paulo. Curso de direito constitucional. 7. ed. rev., atual. e ampl. São Paulo: Malheiros, 1997.

CANOTILHO, J. J. Gomes. Direito constitucional e teoria da Constituição. 6. ed. rev. Coimbra: Almedina, 1993.

DI PIETRO, Maria Sylvia Zanella. Direito Administrativo. 31. Ed. São Paulo: Atlas, 2018.

ESTADÃO. Economia. Renúncias previdenciárias vão tirar R \$ 54 bi dos cofres do INSS em 2019. Disponível em: https://economia.uol.com.br/noticias/estadaoconteudo/2019/02/04/renuncias-previdenciarias-vao-tirar-r-54-bi-dos-cofres-do-inss-em2019.htm?cmpid=copiaecola. Acesso em: 05 abr 2019. 
FERRAJOLI, Luigi. Por uma teoria dos direitos e bens fundamentais. Trad. Alexandre Salim, Alfredo Copetti Neto, Daniela Cademartori, Hermes Zaneti Júnior, Sérgio

Cademartori. Porto Alegre: Livraria do Advogado, 2011.

HOLMES, S; SUSTEIN C. The Cost of Rights - Why Liberty Depends on Taxes. New York: W.W. Norton \& Company, Inc., 2000.

IBRAHIM, Fábio Zambitte. Curso de Direito Previdenciário. 16. ed. Rio de Janeiro: Impetus, 2011.

KRIEGER FILHO, Marcos. Os Ramos da Seguridade Social: Abordagem sob os Princípios Constitucionais da Seguridade Social . Brusque: Kindle, 2018.

LENZA, Pedro. Direito Constitucional Esquematizado. 22 ed. São Paulo: Saraiva Educação, 2018.

MARTINS, Sérgio Pinto. Direito da Seguridade Social. 13 ed. São Paulo: Atlas, 2000.

MARTINEZ, Wladimir Novaes. Curso de Direito Previdenciário. TOMO II - Previdência Social. 2 ed. São Paulo: LTr, 2003.

VIANNA, Cláudia Salles Vilela, Previdência Social: custeio e benefícios. São Paulo:LTr, 2005 . 